*Doutoranda em Direito pelo Programa de Pós Graduação em Direito, Instituições e Negócios da Universidade Federal Fluminense (UFF). Mestre em Máster en Valoración, Potección y Gestión del Patrimonio Cultural pela Universidad de Vigo (UVIGO). Mestre em Justiça Administrativa pela Universidade Federal Fluminense (UFF). Especialização em andamento em Filosofia Política e Jurídica pela Universidade Estadual de Londrina (UEL). Especialista em MBA em Direito Empresarial pela Fundação Getúlio Vargas (FGV). Bacharel em Direito pela Universidade Federal Fluminense (UFF). Email: marcella.paiva1@ gmail.com

**Doutorando em Água, Sostenibilidad y Desarrollo pela Universidad de Vigo (UVIGO). Doutor em Filosofia pela Universidade Federal do Rio de Janeiro (UFRJ). Mestre em Filosofia pela Pontifícia Universidade Católica do Rio Grande do Sul (PUCRS). Bacharel em Direito pelo Centro Universitário Plínio Leite (UNIPLI). Graduado em Filosofia pela Universidade de Passo Fundo (UPF). Email: gilvanluizhansen@id.uff.br

***Mestre em Sociologia e Direito pela Universidade Federal Fluminense (UFF). Especialista em Direito Previdenciário pelo Instituto Latino-Americano de Direito Social (IDS). Especialista em MBA em Gestão Empresarial em Tributação e Contábil pela Universidade Federal Fluminense (UFF). Especialista em Direito Tributário e Legislação de Impostos pela Universidade Estácio de Sá (UNESA). Especialização profissionalizante em Direito Tributário pelo Instituto Brasileiro de Estudos Tributários (IBET). Bacharel em Direito pelo Instituto Metodista Bennett (IMB). Email: jusfederal.brilhante@, gmail.com

\section{DEMOCRACIA E PODER JUDICIÁRIO: ESTUDO SOBRE LEGITIMIDADE E INSTITUCIONALIZAÇÃO DA OPINIÃO E DA VONTADE}

\author{
DEMOCRACY AND THE JUDICIAL BRANCH: A GLIMPSE OF \\ LEGITIMACY AND THE INSTITUTIONALIZATION OF OPINION \\ AND WILLINGNESS
}

\section{Marcella da Costa Moreira de Paiva* Gilvan Luiz Hansen** Simone Brilhante de Mattos***}

Como citar DE PAIVA, Marcella da Costa Moreira. HANSEN, Gilvan Luiz. DE MATTOS, Simone Brilhante. Democracia e poder judiciário: estudo sobre legitimidade e institucionalização da opinião e da vontade. Scientia Iuris, Londrina, v. 24, n. 3, p. 50-72, nov. 2020. DOI: 10.5433/2178-8189.2020v24n3p50. ISSN: $2178-8189$.

Resumo: O Poder Judiciário consiste no único poder estatal em que não há a participação da população na escolha de seus membros, sofrendo com um déficit democrático neste sentido. Adicionalmente, apresenta um sistema de controle pautado na própria instituição, seja o controle interno dos tribunais ou do Conselho Nacional de Justiça, órgão de autonomia relativa de natureza administrativa. Tais sistema de fiscalização e supervisão implementados sofrem com entraves pelos próprios membros do Poder Judiciário. O poder em questão não apresenta mecanismos de controle social e de gestão participativa, os quais são essenciais para a implementação de uma democracia institucional. Ademais, o controle gera maior credibilidade para o sistema perito, permitindo a reprodução de sistemas abstratos. Diante de tal cenário, analisase o sistema de gestão e de controle do Poder Judiciário, a partir de uma perspectiva democrática habermasiana. Deste modo, utiliza-se o método indutivo e a metodologia bibliográfica, com o propósito de examinar os planos de gestão e a institucionalização da opinião e da vontade no âmbito do Judiciário.

Palavras-chave: Poder Judiciário; Conselho Nacional de Justiça; Jürgen Habermas; democracia; gestão participativa. 
Abstract: The Brazilian judicial branch is the only branch of government in which the people do not vote for its members. In this regard, it suffers a severe democratic deficit. Moreover, its control system pertains to the institution, namely from a courts internal controls and the Brazilian National Council of Justice, which is an administrative entity with relative autonomy. Furthermore, its current inspection and supervision system suffers obstacles because of current judiciary members. Additionally, it does not have mechanisms for social control and participatory management, which are essential for implementing an institutional democracy. Apart from that, better governance also generates better credibility for its expert system, allowing it to function properly. From a Habermasian democratic perspective, this study investigates the judiciary's management and control system. Finally, it uses the inductive method and the bibliographic methodology to examine management plans and the institutionalization of opinion and willingness within the Judiciary.

Keywords: Judicial Branch; Conselho Nacional de Justiça; Jürgen Habermas; democracy; participative management. 


\section{INTRODUÇÃO}

O debate sobre a democratização do Poder Judiciário reúne, de um lado, os favoráveis ao seu controle do Judiciário, com mudanças na função de gestão, financeira e orçamentária. E, de outro lado, há o discurso de resistência voltado para o temor de se abalar a independência dos poderes, consequentemente a autonomia do Judiciário. Tal discussão permaneceu presente e pode ser verificado pelas constantes ações de controle de constitucionalidade, principalmente relativas ao questionamento da competência do Conselho Nacional de Justiça (CNJ).

Neste sentido, existem, no Poder Judiciário, resistências e tensões próprias de um sistema perito, dotado de conhecimento específico, e que irradiam seus efeitos na gestão pública do Poder Judiciário, através das resoluções internas do CNJ, e do acesso às informações ao cidadão. No Brasil, há a adoção do regime democrático e não se poder olvidar desta questão na análise modelo de gestão e de controle ao tratar do Poder Judiciário, ainda mais considerando que os seus membros não são escolhidos pela população. Este fato demanda a implementação de mecanismos democráticos.

Diante disto, deve, inicialmente, analisar o que se entende por democracia, a partir das contribuições de Jürgen Habermas. O modelo de democracia deliberativa não se limita meramente ao direito de voto, sendo necessário a participação mais direta e criticamente na atuação das instituições públicas. Ainda neste caminho, a análise do sistema do Judiciário, como sistema perito exposto por Anthony Giddens complementa o referencial teórico, mediante o qual esclarece com propriedade as relações sociais na modernidade; e como a estrutura do Judiciário compõe os sistemas abstratos entendidos como sistema perito possuindo corpo técnico ou especialistas com competência profissional.

Posteriormente, passa-se a examinar o Conselho Nacional de Justiça, criado para trazer democratização ao Poder Judiciário, e os planos estratégicos do CNJ, STJ e TRT-RJ, à luz do referencial teórico. Com isto, tem-se como objetivo analisar tais planos e o CNJ como órgão de controle do poder em questão, frente à democracia de espaço da opinião e da vontade do cidadão. Para tanto, utiliza-se do método dedutivo e a pesquisa bibliográfica como procedimento técnico, partindo do exame doutrinário e normativo.

\section{DEMOCRACIA, GESTÃO PARTICIPAÇÃO E INSTITUCIONALIZAÇÃO DA FORMAÇÃO DA OPINIÃO E DA VONTADE}

Parte-se da premissa que democracia consiste em um termo que recebe variadas acepções, principalmente, a depender do sistema e do modelo considerado. De forma geral, consiste no governo pautado na soberania popular, na participação do povo em determinado grau nas decisões tomadas pelo Estado. Neste passo, cumpre analisar o ponto em questão, sopesando-o nas formas de gestão da administração pública e nas possibilidades de institucionalização de mecanismos de engajamento popular na atividade estatal; destacando a teoria habermasiana e o entendimento 
de uma política dialógica, como modelo de democracia deliberativa, baseada nas condições comunicacionais estabelecidas entre instituições públicas e concernidos.

\subsection{Democracia e confiança na atividade estatal}

O conceito de democracia, independentemente de adoção de modelo liberal ou republicano, implica participação da população e soberania popular, podendo ambos variar na forma e na gradação dentro do formato escolhido (BOBBIO, 1986, p. 18; CANOTILHO, 1998, p. 289). Como será visto no terceiro subtópico, o modelo pode, inclusive, modificar o modo de comunicação do Estado com os cidadãos.

Feitas as considerações gerais, deve-se diferenciar os modelos liberal e republicano e apresentar a alternativa trazida por Jürgen Habermas para ampliar a participação da população, o modelo deliberativo.

O primeiro mencionado tem base no liberalismo, no qual se pretende a limitação da atuação do Estado sobre a vida privada e do governo, a partir do ordenamento jurídico, e a garantia de liberdades individuais. O modelo liberal busca conciliar a sociedade, o mercado e o Estado, de modo a alcançar a consecução dos interesses sociais (HABERMAS, 2002).

República, por seu turno, tem base na Grécia e na Roma Antiga, advindo da expressão latina res publica, que significa coisa do povo. Desta forma, o poder político no modelo em questão pertence ao povo (COMPARATO, 2004). O modelo republicano estruturado no espaço público com eixos comunicacionais estabelecidos com a sociedade; que se organiza legitimando o Estado (HABERMAS, 2020).

Aqui, propõe-se a adoção de um modelo de caráter procedimental, a democracia deliberativa, ao passo que viabiliza a participação da população em diversas esferas do processo administrativo no Estado, a partir da criação de mecanismos de opinião e vontade. A aplicação possui ainda maior relevância quando se refere a órgão, entidade ou poder estatal em que não há participação social na escolha de seus membros, como é o caso do Poder Judiciário.

O modelo proposto por Habermas busca institucionalizar a participação da sociedade nas decisões tomadas pelo estado, de forma a viabilizar que os concernidos avaliem os atos governamentais, seus efeitos e consequências. Neste passo, depende da criação de espaços de esfera pública da opinião e de vontade para desenvolvimento de um discurso, pautado na racionalidade comunicativa (HABERMAS, 2002). Para a formação destes espaços, é essencial o respeito aos pressupostos discursivos e democráticos, bem como a estruturação dos meios para tanto.

Diante destas questões, o poder público deve facilitar o controle e a participação do povo na atividade estatal para seguir com legitimidade e com confiabilidade. O sistema estatal é formado por diversos subsistemas, que possuem uma lógica própria, como a do Poder Judiciário, veiculador da democracia.

Neste sentido, indaga-se a existência de um déficit entre direito subjetivo e público, diante da estrutura burocrática/administrativa do Poder Judiciário. Sua estrutura é delineada tanto por 
sistemas, como por subsistemas que são formados por pessoas dotadas de conhecimento técnico e competência por si próprio, sendo um sistema perito, necessitando e dependendo da confiança, à luz dos ensinamentos de Anthony Giddens. Isto é, o poder estatal em questão necessita da capacidade de se acreditar, de ter fé em alguém ou em algum princípio (GIDDENS, 1991, p. 37).

Neste segmento, a confiança somente pode ser adquirida pelo Poder Judiciário, como um sistema perito, pela realização das expectativas dos jurisdicionados durante sua atuação nas funções típicas e atípicas. Os seus atores, magistrados, servidores, e demais técnicos, representam o poder em suas relações e são essenciais mecanismos de salvaguarda do exercício da função com base em sua competência profissional (GIDDENS, 1991, pp. 97-98). O estabelecimento de uma dependência dos mecanismos citados com a questão de se conquistar a confiança do cidadão nos sistemas abstratos é vislumbrado na análise da relação comunicacional do Judiciário, seja através do seu portal da transparência, seja no âmbito do controle.

Por conseguinte, imperiosa a institucionalização dos meios de formação discursiva da opinião e da vontade para o estabelecimento de uma democracia com efetiva participação dos concernidos, bem como a legitimidade e confiança na administração pública, baseada na possibilidade da ação comunicativa. Deste modo, há a necessidade de transparência, pautada na responsabilidade, e controle da atuação das instituições públicas. Os elementos citados possibilitam que a população tenha conhecimento da atividade estatal, o que permite sua informação, fiscalização e participação nos debates travados entre sistema e mundo da vida. Tais aspectos implicam a adoção de uma plataforma de estratégia de gestão administrativa por parte da administração pública.

\subsection{Gestão estratégica versus gestão participativa}

A gestão das organizações contemporâneas, especialmente no serviço público brasileiro, ainda se encontra estruturada na concepção clássica das escolas como a de Taylor, Ford e Fayol. Tais escolas possuem fundamento na perspectiva liberal e voltam-se para eficiência e redução de custos no desempenho da atividade, seja esta empresarial ou estatal. A adoção de modelos de caráter mercadológico pelas instituições, de forma geral, tem como pano de fundo a colonização do mundo da vida pelos sistemas, o que resulta na dominação da razão voltada para os fins estabelecidos nestas organizações.

A necessidade de otimizar a estrutura organizacional para que venha funcionar com mais eficiência continuam a ser o objetivo da gestão estratégica e, por isso, precisa contar com as pessoas que lá atuam. Ademais, cumpre destacar que os modelos de gestão estratégica chegaram ao esgotamento na década de 1970, com o aparecimento das formas de gestão social e participativa, tanto no âmbito das entidades privadas quanto na administração pública (RAMOS, 1984, p. 181).

O Brasil e suas instituições públicas seguem tal tendência. O Estado brasileiro vem sofrendo, desde a década de 1990, sucessivas reformas, de amplitude constitucional e normativa, direcionadas para a diminuição da estrutura estatal e o aumento da eficiência, sendo o processo denominado de reforma gerencial (BRESSER-PEREIRA, 2000). Com isso, buscou-se a modificação 
da própria gestão do Estado, com intuito de trazer melhoria na qualidade da prestação de serviços estatais e viés democrático (BRESSER-PEREIRA, 2000). Contudo, o modelo de Bresser-Pereira que visava afastar o neoliberalismo tem gradativamente se aproximado do caráter neoliberal.

Neste contexto, a gestão estratégica que foi adotada como modelo de planejamento do Conselho Nacional de Justiça e utilizada em toda estrutura sistêmica do Poder Judiciário possui como característica a não diferenciação do modelo de gestão tradicional de competência técnica e eficiência, estabelecendo uma relação hierárquica e autoritária no qual o poder público se impõe à sociedade que deveria servir, o que no entendimento de Fernando Tenório:

Apesar desta caracterização dos modelos fundamentados na análise de sistemas não configurar uma realidade, ainda assim ela assinala certas tendências orientadas para interesses técnicos, antes que sociais. Assim, vista dessa perspectiva, a tecnocracia é um fenômeno elitista que resulta da projeção da racionalidade instrumental sobre a gestão do Estado e/ou organização sob a epistemologia da teoria tradicional. Por se utilizar da ação gerencial do tipo monológica, ela é autoritária, na medida em que substitui a ideia de associação de indivíduos livres e iguais pela ideia de uma sociedade isenta de sujeitos. Na gestão estatal, a tecnoburocracia toma-se antidemocrática, quando não valoriza o exercício da cidadania nos processos das políticas públicas e, na gestão empresarial, quando não estimula a participação do trabalhador no processo decisório do sistemaempresa (TENÓRIO, 1998, p. 14-15).

Logo, a gestão estratégica implementada nestes moldes possui uma visão objetivante, ao considerar, o outro, fora de suas relações como se "adversário" fosse. Sendo assim, nas sociedades contemporâneas o quantitativo supera o qualitativo, herança dos sistemas típicos do taylorismofordismo, onde a ação administrativa é utilitarista, fundada em cálculos de meios e fins, onde a estrutura é baseada na autoridade formal. Neste tipo de sistema, a organização determina regras de funcionamento e o Estado se impõe sobre a sociedade. É uma combinação de competência técnica e atribuição hierárquica, o que produz a essência do comportamento tecnocrático, no qual a hegemonia do poder técnico ou tecnoburocrático se manifesta tanto no setor público, quanto no privado.

Em algumas situações, observam-se chefias que encaram aqueles que estão "sob suas ordens" (subordinados) - portanto, em assimetria funcional como seres cujo status enquanto humanos é também assimétrico. Tal atitude, de caráter objetivante, afasta do ambiente institucional a simetria contida na relação $\mathrm{EU} \leftrightarrow \mathrm{TU}$, reduzindo o outro à condição assimétrica de terceira pessoa (ele ou isso), de coisa, cujo significado está restrito à mera utilidade e que não vislumbra a idéia de dignidade da pessoa humana (HANSEN, 2015, p. 60).

A gestão participativa viabiliza uma análise diferenciada, sob enfoques distintos, podendo ser político, técnico e econômico, dentre outros campos, realizando o princípio democrático. Mediante o modelo de gestão em questão, a administração da instituição considera o aspecto humano, interno e externo, considerando a opinião e a vontade dos envolvidos, em consonância 
com a democracia e com a dignidade da pessoa humana (RAMOS, 1984).

Portanto, pensar em diversas perspectivas de gestão nas instituições públicas implica romper com as antigas formas de visão das soluções no campo da gestão estratégica. Busca-se uma forma de democracia compartilhada entre o Estado e a sociedade. Assim, em se tratando de gestão estratégica, as mudanças e os desafios precisam estar alinhados aos desafios requeridos pelo estado democrático de direito, e este é mais um grande desafio do Poder Judiciário.

Tenório (1998, p. 16) parte da observação das relações na sociedade, especialmente dos fenômenos políticos, sociais e econômicos, considerando que o protagonista desta relação deva ser o cidadão como participante e legitimador da democracia. Este é o sujeito privilegiado como interlocutor daquilo que interessa na sociedade e nas demandas do Estado-administração.

Nesta conjuntura uma conceituação de intercomunicação entre poder público e cidadão pode ser analisada na obra A inclusão do outro, Habermas (2002), onde apresenta duas concepções de democracia, a liberal e a republicana, pontuando elementos negativos e positivos, onde a proposta um modelo de democracia participativa, através da intersubjetividade e entendimento mútuo entre os cidadãos. Portanto, o cidadão é o sujeito privilegiado da vocalização daquilo que interessa às questões entre sociedade e administração pública.

O mesmo autor destaca a ação comunicativa, conforme explicitada em sua teoria que, sem perder de vista o progresso técnico-científico, engendra uma gestão participativa diferenciada da estratégica, baseada na comunicação que não está baseada em relação monológica e autoritária, mas sim pelo gerenciamento dialógico e participativo, utilizando-se como procedimento o agir comunicativo e o entendimento mútuo (TENÓRIO, 1998, p. 12-13).

Ressalta-se que o Poder Judiciário possui um déficit democrático pela ausência de mecanismos procedimentais de participação da população na escolha dos seus, diferentemente do que ocorre nos Poderes Executivo e Legislativo. Deste modo, cumpre viabilizar meios para trazer maior transparência na sua atuação e para implementar a participação popular, em prol de um poder democrático.

\subsection{Legitimidade e institucionalização da opinião e da vontade}

Ao discorrer sobre uma acepção mais geral sobre legitimidade, Goyard-Fabre (2002,

p. 274) afirma que ela se constitui na proteção contra o capricho e/ou a anarquia, e contra a arbitrariedade ou a insensatez. $O$ direito político moderno deve suprir a necessidade do cidadão em segurança, confiança e coerência, haja vista que a legitimidade deve possibilitar, na esfera da ação cotidiana, a seriedade e a credibilidade, pois a pretensão legitima é aceitável e, assim, “a legitimidade traz em si a marca do justo. É, portanto, acompanhada de autoridade" (GOYARDFABRE, 2002, p. 298).

A pensadora destaca que vivemos em crise de legitimidade e acrescenta que, segundo Habermas, esta crise está voltada para a preocupação democrática e a coesão da sociedade. Se a confiança se instaura nos pontos de referência e eficácia procurados pelas massas sociais, ela torna 
possível o acatamento e a obediência daqueles que são governados. Por isso, o mundo jurídicopolítico é indicador de precariedades e de vulnerabilidades, constituindo-se de expectativas mais numerosas, exigentes e contraditórias das populações.

Ainda salienta, "que a legitimação não poderia se fechar no 'círculo mágico' descrito por Weber" (GOYARD-FABRE, 2002, p. 298). Mostra que a aceitação e o consenso pretendido pelo Estado estão longe de supor somente a racionalidade da ordem jurídico-política. Isto porque a legitimidade constitucional, ligada à noção de validade do sistema, só possui sentido em relação à estrutura legal do ordenamento jurídico do Estado. Mas isto tem analogia com a legitimidade formal e não substancial, como uma grandeza puramente racional, que é distante dos fins e valores do direito político (GOYARD-FABRE, 2002, p. 298).

Por sua vez, Habermas (2012, p. 484) nesse sentido, irá conceituar legitimidade como a capacidade de ser reconhecido um ordenamento político, e a pretensão de legitimidade se conecta com a integração social da sociedade através da identidade normativa, mas de legitimidade não está na legalidade, pois a concepção habermasiana de legitimidade se encontra conectada ao princípio da cidadania, da soberania popular, como sendo uma aceitação e consentimento através de uma ação comunicativa.

Sobre legitimação Habermas (2012, p.224) esclarece que:

As legitimações servem para satisfazer essa pretensão, ou seja, para mostrar como e por que instituições existentes (ou propostas) estão aptas a empregar a força política, de modo a realizar os valores constitutivos da identidade de uma sociedade. $O$ fato de que as legitimações convençam ou mereçam a crença depende certamente de motivos empíricos; mas esses motivos não se formam de modo autônomo com relação a força de justificação, a ser formalmente analisada, que é própria das legitimações, ou, como se pode dizer - do potencial de legitimação ou dos motivos que possam ser mobilizados. [...] Por 'níveis de justificação', desse modo, entendo as condições formais de aceitabilidade dos fundamentos, que conferem eficácia às legitimações; em suma, que lhes conferem a força de obter consenso e de formar motivos.

Existe uma força ilocucionária de quem fala para motivar o ouvinte a aceitar seu ato de fala. Os sujeitos aptos a falar e a agir, ao se entenderem mutuamente, podem estabelecer uma comunicação entre sistema de mundos que se supõe compartilhada.

Em continuidade, a ação comunicativa aqui entendida como a ação voltada para os sujeitos capazes de linguagem, que desejam estabelecer uma comunicação buscando entender sobre uma situação; e coordenar, de comum acordo, seus planos de ação. Em conformidade com Tenório (1998, p.16), quando explana sobre os dois modelos de "gestão social" e "gestão estratégica" salienta que este modelo adota a tecnocracia utilizada na administração pública e voltada para uma racionalidade instrumental com características autoritárias e ação comunicativa monológica. Entretanto, a gestão social pode ser orientada pela racionalidade comunicativa, com seus atores estabelecendo procedimentos voltados para o consenso.

Esta questão requer que haja a inserção de mecanismos de permitir a participação e o 
controle da população em geral, viabilizando o exercício da democracia nas instituições. A realização do princípio em questão se faz essencial em um Estado que adere o regime democrático e que o faz de forma expressa na Constituição Federal. Ademais, deve-se ressaltar que a implementação de uma modelo de gestão social de caráter participativo deve ocorrer em todas as esferas do Estado, em especial no Poder Judiciário, único poder estatal que a população não participa da escolha de seus membros.

\section{PLANO DE GESTÃo ADMINISTRATIVA DO JUDICIÁRIO, TRANSPARÊNCIA E CONTROLE}

Frente ao referencial teórico explicitado, nota-se que a democracia infere a institucionalização de meios de participação, de opinião e vontade, da população nas atividades da administração pública. Isto resulta a necessidade de adoção de um modelo de gestão social com efetiva viabilização destas questões.

A Carta Magna de 1988, em seu art. $1^{\circ}$, caput, enuncia que a República Brasileira é um estado democrático de direito, o que reitera a necessidade de participação popular na administração pública brasileira. Destarte, não basta que o Estado seja limitado e atue conforme o direito. Demanda a necessidade de garantia e a consecução da democracia e dos direitos fundamentais. Como visto anteriormente, a democracia se baseia na participação do povo nas decisões políticas e administrativas e no controle do Estado (CANOTILHO, 1998).

Comparato (2004) assevera que tal participação se dá também pelo controle, que deve ser horizontal e vertical. O primeiro é feito pelos próprios entes públicos e seus órgãos, vinculado ao princípio da separação de poderes (COMPARATO, 2004). Insere-se aqui os controles interno e externo, conforme uma das classificações feitas pela doutrina administrativista. $O$ vertical, por sua vez, está fundado na soberania popular, sendo essencial que haja um órgão de representação popular e o controle da atuação do Poder Judiciário. Para implementá-los, requer-se publicidade dos atos administrativos lato sensu e transparência.

O controle social consiste, desta forma, em um mecanismo de participação democrática da população na atuação do Estado, que, com meios de implementação de locais de opinião e vontade, pode gerar legitimidade e credibilidade. Com isto, a publicidade e a transparência possibilitam o controle pela sociedade civil e são instrumentos em que geram confiabilidade, a qual viabiliza a legitimidade do Estado e de seus órgãos na modernidade. O Poder Judiciário, por meio de sua função típica - a atividade jurisdicional, consiste em um dos instrumentos de controle horizontal externo e ainda social. No primeiro caso, ocorre quando atua fiscalizando e controlando atos dos demais poderes e, no segundo, se dá pelos remédios constitucionais, especialmente, pela ação popular.

Em sua atuação, sofre controle externo dos tribunais de contas e do Poder Legislativo, em conformidade com os arts. 70 e 74, da Constituição Federal. O controle interno se dá, na atividade jurisdicional, pelos órgãos jurisdicionais hierarquicamente superiores. Não há, no entanto, nenhuma previsão específica quanto a mecanismos de controle social do próprio Poder 
Judiciário, se mantendo o déficit democrático do desse poder estatal.

A atividade administrativa do Poder Judiciário foi regulamentada no art. 99 da Constituição Federal, não podendo ser interpretada apenas como um princípio da legalidade administrativa. Devem ser aplicados os demais princípios constitucionais e legais da administração pública, assim como os princípios e fundamentos da República Federativa do Brasil. Com tal dispositivo, fica consagrada a autonomia administrativa, financeira e orçamentário do Poder Judiciário, a espelho do previsto para os demais poderes, sem ingerência externa. Contudo, isto não exclui os controles interno, externo e social e tampouco à necessidade de publicidade, transparência e accountability, essenciais para a democratização do Poder Judiciário e para a realização de uma gestão participativa.

Neste diapasão, Slaibi Filho (2016, p. 137) explica que:

Evidentemente, a autonomia administrativa e financeira do Poder Judiciário, assim como as autonomias do Ministério Público e de alguns outros entes essenciais à Justiça, não pode ser interpretada sectariamente de forma a excluir o dever jurídico de seus membros e servidores de cumprir os princípios administrativos que são aplicáveis aos demais poderes em todos os níveis federativos, como se vê no art. 37, caput, da Lei Maior. Frise-se que ter autonomia significa gerir-se pelas normas aplicáveis, não o desapego à ordem constitucional e legal. Ressaltese que as funções administrativas do Poder Judiciário não constituem o seu objeto de atuação ou atividade-fim - que é a prestação jurisdicional -, mas mero instrumento de realização desta atividade, de nítido conteúdo político, exercido por membros do Poder e que não pode se limitar pela função secundária.

Isto é, o desempenho da atividade administrativa pelo Poder Judiciário consiste em uma atípica, secundária, sendo justificada e se pautando como instrumento para a realização da atividade jurisdicional. Durante tal atuação, o poder mencionado deve cumprir com os princípios administrativos, em especial, a legalidade, a impessoalidade, a moralidade, a publicidade e a eficiência, assim como com o princípio democrático. Portanto, deve possuir mecanismos para possibilitar o controle e a participação popular.

Entretanto, o Poder Judiciário não possuía até 2004 um órgão independente voltado para o controle desta atividade de gestão, havendo apenas as auditorias internas e as corregedorasgerais dos tribunais. Quanto às corregedorias, realizam o controle interno disciplinar dos membros do tribunal, mas, na prática, somente se atém à fiscalização da atuação dos juízes de primeira instância (DALLARI, 2008, p. 47).

Neste contexto, cumpre recordar que o processo de reforma do Poder Judiciário, ainda durante o ano 2000, foi arcado por resistências e apoio à possibilidade de um controle ao Poder Judiciário. Frente a reforma gerencial do Estado brasileiro, era necessário a modificação do poder em questão para atender as noções de eficiência e de democracia, resultando na Emenda Constitucional n. 45 de 2004, denominada de Emenda Constitucional de Reforma do Poder Judiciário.

A EC trouxe previsão do princípio da celeridade processual e razoável duração do processo para os processos administrativo e judicial (Art. 5º LXXVIII, da CRFB); da aferição 
de desempenho dos magistrados na decisão sobre promoção (art. 93, II, d, e); da publicidade nos julgamentos (art. 93, IX); de novas vedações para magistrados (art. 95, parágrafo único, IV); a criação do Conselho Nacional de Justiça (art. 103-B), dentre outros. A reforma e a criação do CNJ se pautam na necessidade de maior eficácia na atuação do Poder Judiciário e nos anseios de redução de abuso do poder dos seus atores (FLURH, 2011, p. 242; MALUF, 2013).

O CNJ, nesta direção, foi inserido pela EC 45/2004 na própria estrutura do Poder Judiciário, como órgão de controle da atuação administrativa e financeira do Poder Judiciário e do cumprimento dos deveres funcionais dos juízes (art. 103-B, parágrafo $4^{\circ}$ ) para trazer accountability e executar poder correcional (SADEK, 2001; p. 47; CARVALHO FILHO, 2010, pp. 16-17).

Dentre as suas competências, está o julgamento de processos administrativos disciplinares contra magistrados e a elaboração do Plano Estratégico Nacional do Judiciário. A própria nomenclatura escolhida para o plano de gestão indica que é voltado para a eficiência, se referindo à gestão estratégica, de cunho liberal e em declínio desde os anos 1970. Consequentemente, pode-se inicialmente depreender que consiste em um sistema de gestão de caráter objetivante e instrumental, que não é compatível com o regime democrático.

Neste encadeamento, o Plano Estratégico Nacional do Judiciário será analisado, à luz da fundamentação teórica, com intuito de verificar se aproxima-se de uma gestão participativa e se efetivamente aplica a perspectiva de democratização presente na criação do Conselho Nacional de Justiça.

A Resolução n. 198 de 2014 do Conselho Nacional de Justiça dispõe sobre o planejamento e a gestão estratégica do Poder Judiciário. A normativa apresenta procedimentos a partir de uma visão integrada, alinhada a objetivos, indicadores e metas para que as unidades organizacionais possam planejar suas iniciativas de maneira coordenada (art. $1^{\circ}$ ), os quais deverão estar presentes nos planos.

Visa-se ao planejamento do futuro de forma orgânica, como um conjunto coerente e bem estruturado, considerando as alterações no macroambiente onde se englobam os elementos políticos, econômicos, legais, tecnológicos, sociais e culturais. Logo, ao se delinear o planejamento estratégico, deve-se considerar as necessidades e os interesses entendidos como provenientes das demandas da sociedade, onde também se encontram claramente definidos valores, missão e visão do futuro. Contudo, se baseia fortemente na definição de metas e de avaliação de resultados

A partir destas demandas estruturais, se verificam alguns aspectos internos: pessoas, procedimentos, estruturas de poder, recursos materiais e orçamento; adotando também uma postura crítica aos seus projetos e formas de trabalho. Um dos objetivos principais, entre outros, é a adoção de encarar os desafios internos e externos, enfrentando seus pontos fracos e valorizando seus pontos fortes. O planejamento estratégico procura também definir mudanças significativas que, em médio e longo prazo, melhorem o serviço oferecido aos usuários, sendo ferramenta indispensável à gestão, portanto legalmente previsto em diversas normas.

Percebe-se que o Conselho Nacional de Justiça, mais bem analisado no próximo subtópico, através do seu Plano Estratégico Nacional passou a levar em conta valores que antes não eram 
explicitados mediante objetivos a serem considerados como diretrizes pelo Poder Judiciário. A propósito, foram editadas várias resoluções trazendo como atributos de valor para o Judiciário a transparência, a responsabilidade social e a ética, entre outros atributos a serem seguidos pelo sistema interno dos tribunais de todo Brasil. É inegável que, com a inserção de novos valores, mudanças estão aparecendo nas organizações ligadas à atividade judiciária.

O destaque da atuação do Conselho é relevante, pois ele vem propiciando, em que pese as resistências internas que ecoam na estrutura do Judiciário, a concretização da democratização do Judiciário, através da regulamentação de procedimentos transparentes. Pode-se destacar, para melhor ilustrar a análise do tema, algumas resoluções instituídas:

Resolução $\mathrm{n}^{\circ}$ 70, que criou o Plano Estratégico Nacional do Poder Judiciário; Resolução $\mathrm{n}^{\circ} 128$, resultante da necessidade vivenciada pelo Judiciário de resgatar a confiança e a credibilidade da sociedade, através da implementação e promoção de atributos de valor para a sociedade como a credibilidade, celeridade, modernidade, acessibilidade imparcialidade, transparência, controle social, ética, probidade, responsabilidade socioambiental;

Resolução $\mathrm{n}^{\circ} 102$, que orienta os tribunais para a divulgação na internet de informações as remunerações de magistrados e servidores. A Resolução determina que os tribunais tornem públicos todos os seus gastos, inclusive despesas com passagens, diárias, contratação de serviços e obras;

Para garantir e ratificar esta preocupação, o CNJ publicou a Resolução $\mathrm{n}^{\circ} 151$, que determinou a divulgação nominal da remuneração dos membros e servidores do Judiciário, apresentando-se através de dados a folha de pagamento;

Resolução n ${ }^{\circ}$ 198/2014 do CNJ consolida a transparência trazida como valor a permear o sistema do Judiciário, no sentido de promover a relação participativa do cidadão através da Gestão Estratégica do Judiciário;

Resolução no 308 de 11/03/2020 dispõe sobre a organização das atividades de auditoria interna do Poder Judiciário, sob a forma de sistema, e cria a Comissão Permanente de Auditoria, exercendo a competência do Conselho Nacional de Justiça para o controle administrativo e financeiro do Poder Judiciário.

Por meio das medidas em questão, busca-se a aproximação do Poder Judiciário com os jurisdicionados e a ampliação dos mecanismos de controle e de fiscalização da atuação do poder em questão. Nota-se a preocupação com a transparência e com a accountability, os quais, como visto anteriormente, são condições de possibilidade para o controle social e para a efetivação da democracia na administração pública.

Atualmente, no transcurso de mais de 10 anos de sua criação, o Conselho Nacional de Justiça $(\mathrm{CNJ})$, tendo por base a regulamentação trazida pelo art. 103-B da Constituição Federal, exerce a função de controle externo, com competência constitucional para propor aperfeiçoamento administrativo na política e gestão do Judiciário, bem como fiscalizador do cumprimento e deveres funcionais dos magistrados. Entretanto, os desafios para promover as mudanças são constantes, e o CNJ, ao exercer o controle do Poder Judiciário, vem enfrentando forte resistência ao longo de seus anos de existência.

Uma das atribuições mais visíveis do CNJ é a democratização do Judiciário, levando-se 
em consideração que foi um dos fortes motivos de sua criação. Neste sentido, têm sido grandes as reações e resistências, com inúmeras demandas ajuizadas no Supremo Tribunal Federal. Embora não se pretenda citar todas as demandas neste trabalho, para exemplificação vale destacar os seguintes julgados que demonstram os contornos que envolvem o controle do Poder Judiciário:

A ADIN 3.367/2005 foi ajuizada pela Associação dos Magistrados Brasileiros (AMB) contra a criação do CNJ, sob a arguição de que: 1) ofensa aos princípios da separação e independência dos poderes da República; 2) ofensa ao pacto federativo. A maioria dos membros do STF julgou a aludida ação totalmente improcedente (Franco). O entendimento dos ministros do STF foi pela improcedência daquela ação, entendendo-se que tanto a indicação pelo Legislativo, quanto a composição do Conselho por membros do Ministério Público e da Advocacia não fere a Constituição Federal;

A ADI 4.485/2007 ajuizada pela Associação dos Magistrados Brasileiros (AMB) alegando a inconstitucionalidade da Res. 70 de 2007 pela ausência de competência do CNJ para dispor sobre processo administrativo disciplinar aplicável aos magistrados. A ação foi prejudicada pela revogação da resolução pela Res. 135 de 2011 do CNJ (STJ, AD I4485/DF, Rel. Min. Joaquim Barbosa, publicada em 09/03/2012).

Em 2011, outra ADI foi julgada pelo STF, agora a de $n^{\circ} 4.638 / 2011$, que questionava a Resolução $n^{\circ}$ 135/2011 do Conselho Nacional de Justiça que regulamentou os procedimentos administrativos disciplinares da magistratura nacional. A Associação dos Magistrados Brasileiros (AMB) questionou sobre a incompetência normativa do CNJ para editar resoluções aplicáveis a toda a magistratura nacional. O STF decidiu que o Conselho é órgão nacional, que seus julgamentos devem ser transparentes e a possibilidade de edição de normas pelo CNJ deve vincular os Tribunais.

A última ação direta de inconstitucionalidade é consid

erada relevantíssima para a história do $\mathrm{CNJ}$, sendo o momento de confirmação da constitucionalidade da competência normativa do órgão (MELO, HERCULANO, MONTENEGRO, 2020).

Diante do cenário, verifica-se os desafios do Conselho Nacional de Justiça e do Poder Judiciário na aproximação da gestão e do controle daqueles imprescindíveis em um regime democrático. Nota-se que há um avanço no sentido de trazer maior transparência, informação, fiscalização e responsabilidade para atuação na atividade administrativa atípica do poder, o que viabiliza o controle social e a participação da população.

Todavia, não há, ao menos, nas resoluções do CNJ e legislações infraconstitucionais disposições no sentido de efetivar a participação ou de criar algum órgão de representação popular no Poder Judiciário. Portanto, não se constata a estruturação de mecanismos de formação discursiva de opinião e de vontade no Poder Judiciário.

1 Relator Ministro Cezar Peluso. 


\section{ANÁLISE DO PLANO ESTRATÉGICO NACIONAL DO JUDICIÁRIO E DOS PLANOS DO STJ E TRT-RJ}

À luz do mencionado anteriormente, a democracia não se limita ao direito de voto e de ser votado (capacidade eleitoral ativa e passiva), depende um amplo engajamento da sociedade civil na atividade estatal, seja mediante a participação nas decisões ou pelo controle social.

O Estado brasileiro deve implementar um modelo de democracia de caráter procedimental em todas as esferas e poderes, viabilizando a participação da sociedade civil a partir da criação de espaços de esfera pública.

Para tanto, é necessário a estruturação de um modelo de gestão social de caráter participativo no Poder Judiciário, voltado para a institucionalização de mecanismo de opinião e vontade, que reconstrua a racionalidade comunicativa nos seus órgãos. Deste modo, é essencial a modificação da lógica da gestão do Estado brasileiro, de caráter estratégico, introduzido pelas reformas gerenciais

Frente a necessidade de democratização e de fiscalização do poder em questão, foi criado o CNJ com o intuito de democratização para o Poder Judiciário, mediante transparência, publicidade e controle interno.

Dentre suas atribuições, está a estruturação do plano de gestão estratégico, com base no qual os demais órgãos do Poder Judiciário editam seus próprios planejamentos. O art. 12 da Res. 198 de 2014 dispõe que serão realizados encontros nacionais para a definição da estratégia, valores, missões, metas e diretrizes, bem como para avaliá-las.

No tocante aos Encontros Nacionais do Poder Judiciário, há a participação dos tribunais, representados por seus respectivos presidentes, sob a coordenação do Conselho Nacional de Justiça, com a realização de palestras, entrega dos prêmios de qualidade, análise dos resultados do ano anterior e definição de novas metas.

Nos arts. 13 e 14, também se refere ao banco de boas práticas, pelos quais os servidores e membros podem enviar sugestões. Entretanto, não se menciona a possibilidade de consulta à sociedade civil, sistemas de ouvidoria, audiência pública ou a participação de representantes da população no planejamento.

Neste tópico, a abordagem se direciona para a análise do Plano Estratégico Nacional do Judiciário elaborado pelo Conselho Nacional de Justiça dos anos de 2010-2014 e 2015-2020 e dos planos de gestão do Superior Tribunal de Justiça e do Tribunal Regional do Trabalho do Rio de Janeiro, à luz da democracia e da necessidade de participação democrática. Neste passo, será verificado o atendimento do plano à perspectiva de democracia habermasiana e à gestão participativa.

\subsection{Plano estratégico nacional do judiciário}

O Plano de 2010-2014 do Conselho Nacional de Justiça foi estruturado com a missão 
de trazer eficiência, efetividade e moralidade para a prestação jurisdicional, se pautando em sete pilares: fiscalização e correição; alinhamento e integração; atuação institucional; eficiência operacional; gestão de pessoas; infraestrutura e tecnologia e orçamento. Os quatros primeiros são relativos aos processos internos e os demais referentes a recursos.

No tocante à fiscalização e correição, busca-se a atuação em conformidade com os princípios constitucionais e a execução do poder correcional, evitando desvios de poder. Neste ponto, a atuação do CNJ se voltou para o estabelecimento de metas de julgamento, para a realização de inspeção ou correição nos tribunais, a publicação das ações correcionais e planejamento das inspeções. Todos os aspectos tiveram bons ou ótimos desempenhos no período de 2010-2014.

Ademais, há a previsão de fortalecimento da comunicação com o público externo, sendo esta pensada para a informação sobre a função do Poder Judiciários, aspectos processuais e administrativo e dados financeiros e econômicos. No que tange à comunicação social, a Portaria n. 47 de 2014 sugeriu a criação de páginas de redes sociais para os tribunais, como Facebook, Linked In, etc ${ }^{2}$. Entretanto, não basta a criação de páginas se não há a possibilidade de interação e de consideração dos pontos trazidos.

No Planejamento Estratégico de 2015-2020, a missão prevista não se centra unicamente na ideia de efetividade, buscando ainda a unidade do Poder Judiciário e políticas judiciárias para a promoção da justiça e da paz social. Neste passo, se nota uma modificação em um prol da concepção de gestão participativa, sem se ater apenas a perspectiva de metas. Dentre os valores, está prevista a transparência, em consonância com o princípio da publicidade, e, nos objetivos estratégicos, está a promoção dos direitos de cidadania para fortalecimento do estado democrático de direito.

Em ambos os documentos, há menção à transparência e à publicidade, as quais são cumpridas com a possibilidade de acesso às decisões, portarias e resoluções do Conselho Nacional de Justiça. Desta forma, a comunicação do Poder está voltada apenas para a apresentação da sua atuação, sem a possibilidade de mecanismos de opinião e vontade. Não se verifica medidas capazes de integrar a população ao Poder Judiciário, como audiências públicas, ouvidorias etc.

Adicionalmente, fala-se em prestação de contas e accountability no tocante a recursos e orçamento. Tais questões, junto com o acesso à informação, possibilitam que os administrados façam o controle social. Contudo, em nenhum dos documentos há previsão de algum mecanismo de participação ou representação popular, seguindo o déficit democrático do Poder Judiciário. Por outro lado, há avanço na ampliação do controle externo na atuação administrativa e orçamentária por parte do CNJ.

Deste modo, não se vislumbra a efetivação de uma gestão social, a partir dos planos estratégicos do CNJ analisados, ainda se prendendo fortemente à definição de metas e de indicadores para sua avaliação. Com isto, se aproxima mais da lógica de gestão estratégica, direcionada apenas

2 Com relação às redes sociais do STJ, nota-se que não há possibilidade interação com o órgão do Poder Judiciário no Instagram. Contudo, o Facebook possui uma parte denominada "Fale Conosco" e no Linked In e Twitter, é possível comentar e marcar o tribunal em publicações, mas sem interações nos comentários com o STJ. Da mesma forma, o CNJ e o TRT-RJ possuem suas redes com a mesmas considerações. 
para a eficiência, sem considerar a função do Poder Judiciário no estado democrático de direito e a necessidade da efetivação na democracia na prática.

\subsection{Plano do stj}

O Superior Tribunal de Justiça, desde 1998, realiza a elaboração de planos plurianuais de gestão estratégica, porém somente serão realizados os dois últimos, 2010-2014 e 2015-2020.

O Plano de 2010-2014, criado com base na Res. 70 de 2009, se pauta em três perspectivas: a sociedade; os processos internos e os recursos. No referente ao primeiro, se destaca a necessidade de atendimento às demandas e expectativas da sociedade. Nos processos internos, trata-se, dentre outras questões, de melhoria na comunicação, gestão administrativa, celeridade e promoção da cidadania. A transparência e a ética são previstas como valores no plano, sem grandes detalhamentos sobre a definição de mecanismos para garanti-las.

Seguindo a Resolução do CNJ n. 198 de 01/07/2014, que dispõe sobre o Planejamento e a Gestão Estratégica no âmbito do Poder Judiciário, o Superior Tribunal de Justiça elaborou o Plano 2015-2020. Os valores mencionados também estão dispostos no plano de 2020, havendo maior especificação sobre transparência, como a necessidade de disponibilização de informações para viabilizar a participação e o controle social. As perspectivas também se mantiveram as mesmas, mas houve maior destaque para a atuação nos processos internos para a prioridade para processos sobre corrupção e improbidade administrativa.

Bem como apontado na análise dos planos do CNJ, há previsão dos elementos que permitem a participação e o controle popular, mas falta a institucionalização de meios para implementá-los.

\subsection{Plano do trt-rj}

Em conformidade com as exigências de planos estratégico previstas na Resolução 70 de 18/03/2009 e Resolução n. 198 de 01/07/2014 do Conselho Nacional de Justiça, o Tribunal Regional do Trabalho da $1^{\text {a }}$ Região também elaborou planos em 2010-2014 e 2015-2020.

No Plano 2010-2014, apresentou um modelo bastante similar ao do Superior Tribunal de Justiça do mesmo período, com a previsão das mesmas perspectivas e descrições destas. O tribunal menciona a realização de uma análise interna e externa para verificar suas ameaças, oportunidades, fraquezas e forças, mas não delineia a fonte de pesquisa. Dentre as ameaças, realça a imagem desgastada do Poder Judiciário perante a sociedade. Nos valores, prevê ética, transparência e credibilidade, sem mais explicitações sobre o tema.

Nos objetivos estratégicos, prevê a necessidade de melhoria da comunicação com o público interno e externo, entro de atuação institucional. Ademais, prevê a promoção da efetividade, excelência na gestão, celeridade. O tribunal dispõe ainda sobre indicadores para avaliar os objetivos, sobre projetos e ações. No que tange a aprimoração da comunicação, vislumbra a modificação do portal eletrônico, a criação de canais de ouvidoria, de glossário jurídico e de manual do servidor.

De forma geral, o Plano 2015-2020 se assemelha bastante ao plano anterior, prevendo 
indicadores e metas para os objetivos estratégicos. Sobre transparência, houve a criação de projetos para digitalização dos atos normativos, acórdãos e diários oficiais, sendo verificada melhoria na satisfação do público com os canais de comunicação.

Nos documentos do TRT, não há menção a corrupção e abuso de poder e mecanismo de combate. No entanto, destaca a necessidade de comunicação com o público e traz instrumentos para viabilizá-la, o que demonstra uma maior preocupação com a participação da população com a prestação jurisdicional.

\subsection{Resultados}

Agestão estratégica apresentada pelo Judiciário dispõe em seu planejamento procedimentos a partir de uma visão integrada, alinhada a objetivos, indicadores e metas para que as unidades organizacionais possam planejar suas iniciativas de maneira coordenada.

Para a implementação de uma gestão democrática, voltada para o âmbito social, requer-se que, primeiramente, o próprio plano de administração seja resultado de um processo participativo dos envolvidos - da população e dos membros do Poder Judiciário. Tal participação gera maior credibilidade e, consequentemente, legitimidade para o sistema perito em questão. Contudo, o aspecto da integração da sociedade a sua atuação não se limita a este único momento, deve acompanhar todos os atos que englobam as funções típicas e atípicas desse poder estatal.

A gestão estratégica, nos moldes apresentados pela gestão organizacional do Poder Judiciário, não atende aos princípios da gestão participativa, na qual o cidadão reconheça o Judiciário como o legitimador da democracia. Contata-se, apesar dos esforços de ampliação do acesso à informação e de comunicação social, que o caráter democrático da administração judiciária se restringe a este ponto. Os Encontros Nacionais, por exemplo, avaliam a consecução das metas e se volta para a comunidade judiciária e jurídica, mas deveria viabilizar e incentivar a participação da sociedade civil.

Todavia, pela análise dos planos, nota-se que se limita apenas ao acesso à informação e a realização de controle, sem a busca de criação de espaços de esfera pública, voltados para o desenvolvimento de ação comunicativa.

Por meio de pesquisa nos sites do CNJ, STJ e no TRT-RJ, analisou-se no portal o acesso aos planos estratégicos escolhidos. Foi verificada a existência ou não de procedimentos que direcionassem para a ação comunicativa entre a estrutura sistêmica do Poder Judiciário e a sociedade civil, direcionados para os valores institucionais estabelecidos pela gestão estratégica daquela administração pública.

O plano estratégico do CNJ regulamentado pela Resolução $n^{\circ} 99 / 2009$, possui os seguintes atributos de valor institucional: celeridade; modernidade; acessibilidade; transparência; responsabilidade social e ambiental; imparcialidade; ética; probidade. Já o plano estratégico do STJ de 2015-2020 segue basicamente os planos gerais anteriores, especificamente quanto aos valores institucionais que são “aprendizagem contínua - comprometimento - ética - sustentabilidade - 
transparência" (STJ, 2015, p. 16). Enquanto isso, o plano estratégico do TRT da $1^{\text {a }}$ região de 20102014 também segue o modelo do CNJ e STJ em relação aos valores institucionais: acessibilidade; compromisso e participação; credibilidade; eficácia e eficiência; ética; responsabilidade socioambiental; transparência.

Durante o exame da gestão econômica e financeira do CNJ, STJ e TRT-RJ, verificou-se que os portais remetem ao acesso à informação e transparência do CNJ. Indaga-se se as tabelas e gráficos disponibilizados, bem como os demonstrativos de fluxo de caixa, através de planilhas, podem ser entendidos como procedimentos que efetivem uma ação comunicativa e de fácil entendimento, como instituído nas legislações que regulamentam tal procedimento.

Constatou-se efetivamente a inexistência de acesso a informações com visualização fácil e simplificada, embora a transparência e a publicidade sejam pressupostos do CNJ e da própria democracia. Tanto o STJ como o TRT da $1^{\text {a }}$ região seguem a mesma disposição de dados, ao informar detalhes sobre a remuneração, seja dos servidores, seja dos ministros e desembargadores. O TRT da $1^{\text {a }}$ região possui planilhas atualizadas até 2020 com remunerações, empregados terceirizados e contratos.

A regulamentação da transparência e acesso à informação ressalta especificamente que o procedimento do conhecimento e das informações aos cidadãos devem ser veiculados de forma mais didática possível, para proporcionar fácil compreensão, enfim simplificada. Não se nota que esta adoção e cumprimento aos dispositivos normativos estejam sendo concretizados pelo Poder Judiciário, em conformidade com a imensa dificuldade de se navegar nos sites divulgados e obter as informações desejadas, embora se mencione nos planos a necessidade de realização da transparência e da publicidade. Neste sentido, cumpre recordar que o controle social consiste em uma das formas de participação em um regime democrático e que não é efetivado na prática.

Por sua vez, a avaliação efetuada pelo órgão da área técnica do STJ e do TRT-RJ, quanto aos pontos fortes e fracos da infraestrutura tiveram como resultado, o da qualificação da força de trabalho e a da tecnologia existente como sendo pontos fortes. Não se considerou uma avaliação da opinião dos jurisdicionados, sobre a atuação do Judiciário em respeito às regulamentações da transparência, o que suscita a indagação de se aquele Poder tem real interesse na opinião da sociedade.

Finalmente, em se tratando do chamado ambiente externo, a análise efetuada pelo Departamento Técnico do STJ definiu como ameaças as demais estruturas sociais externas ao sistema judicial, talvez porque estejam fora do âmbito e controle da organização institucional do Judiciário. A interpretação advinda do sistema do Judiciário é de que a instituição deve conhecer e monitorar as chamadas "ameaças", como a elevada demanda de processos, que tornam as decisões mais morosas, como também a falta de diálogo com os poderes da República, que dificulta a efetivação das modificações necessárias.

Tal situação desafia refletir se o Judiciário está em busca da democratização em seus procedimentos administrativos e se acompanha as transformações e complexidades de uma sociedade com grande diversidade política, social e econômica, indispensável para a priorização 
da transparência. A regulamentação da transparência por meios normativos possibilita entender que o legislador desejou instituir procedimentos necessários na gestão pública para coibir desvios e ilegalidades, efetuando a dinâmica de informação, conhecimento e esclarecimento à sociedade, como medida de prevenção às anomalias observadas nas instituições públicas.

Destarte, se percebe que há uma tentativa de trazer valores democráticos e gestão social nos órgãos do Poder Judiciário, mediante a disposição sobre instrumentos de comunicação social, transparência, accoutability e controle. No entanto, ainda possui caráter estratégico e não prevê mecanismos de realização de uma democracia de base procedimentalista, em que há a criação de mecanismos de participação nos processos decisórios e, consequentemente, a aproximação da população com espaços de racionalidade comunicativa.

Neste diapasão, há necessidade de abertura dos Encontros Nacionais para a população, seja a partir da participação presencial ou eletrônica, para voltar-se para a sua compreensão e ser capaz de atender seus anseios. Ademais, as ouvidorias, as audiências públicas e o orçamento participativo devem ser implementados e geridos como mecanismos oxigenação democrática para o Poder Judiciário. Outro aspecto relativo à gestão social são as redes sociais, que já existem, mas sem interação e sem respostas para os jurisdicionados. As páginas da internet devem ser utilizadas para auxiliar em um processo de inserção de uma gestão participativa, gerando maior confiabilidade e legitimidade.

\section{CONCLUSÃO}

O enfoque desenvolvido no texto concentra-se no estudo e na análise da transparência na gestão administrativa, financeira e econômica do sistema do Poder Judiciário, a partir da perspectiva da Teoria de Ação Comunicativa engendrada por Habermas (2011).

Com o objetivo de realizar esta proposição, delimita-se o estudo a partir da Constituição Brasileira de 1988, marco regulatório da transparência a ser adotado pelos serviços públicos do país. A análise sobre sua conceituação, tanto no campo administrativo quanto no constitucional, foi de relevo para posterior estudo de sua regulamentação no ordenamento jurídico. Partimos da problematização com base na questão sobre a existência da transparência na gestão do Judiciário, em conformidade com os regulamentos do Plano Estratégico Nacional do Conselho Nacional de Justiça, e como ela se realiza.

Daí o fato de propor uma análise crítica para verificar a efetividade da regulamentação direcionada para a obtenção da transparência e seu vínculo com a participação do cidadão num contexto em que lhe fosse considerado propício. Foi necessário investigar se existe a possibilidade de uma ação comunicativa interna e externa na estrutura sistêmica do Judiciário, procedimento legitimador da democracia.

$\mathrm{Na}$ reflexão suscitada também foram consideradas as gestões estratégicas da gestão do Judiciário e como se efetiva a ação comunicacional desta estrutura, seja internamente ou externamente. Ainda nesta conjuntura, a arena onde se estabelecem as relações entre os atores do Judiciário se afigura em constante tensão e insatisfação, e neste ponto surge também a necessidade 
de uma ação comunicativa e transparente com base em procedimentos intersubjetivos voltados para o consenso.

Em consequência, a legitimação da democracia, como rede de discursos de ações intersubjetivas, formadores de opinião e da vontade juridicamente institucionalizada, não é alcançada. Neste sentido e segundo as teorias analisadas, o Judiciário possui em sua missão institucional a busca da democratização, sendo este desafio a ser superado.

\section{REFERÊNCIAS BIBLIOGRÁFICAS}

AJD. Por uma Lei Orgânica da Magistratura Nacional Democrática. Juízes para a Democracia. Agosto - Outubro 2015, Ano 15 - No 68, ISSN 2358-4653. Disponível em: <http://ajd.org.br/ arquivos/publicacao/88_88_ajd_68.pdf >.Acesso em: 5 maio 2017.

BONAVIDES, Paulo. Curso de Direito Constitucional. São Paulo: Malheiros, 2000.

BRASIL. Constituição da República Federativa do Brasil de 1988. Disponível em: $<$ http://www.planalto.gov.br/ccivil_03/constituicao/constituicaocompilado.htm $>$. Acesso em: 8 jul. 2017.

BRASIL. Lei $\mathbf{n}^{\circ}$ 12.527/2011, de 18 de novembro de 2011.Regula o acesso a informações previsto no inciso XXXIII do art. 5ำ, no inciso II do $\S 3^{\circ}$ do art. 37 e no $\S 2^{\circ}$ do art. 216 da Constituição Federal; altera a Lei no 1.112 , de 11 de dezembro de 1990; revoga a Lei no 11.111, de 5 de maio de 2005, e dispositivos da Lei no 8.159, de 8 de janeiro de 1991; e dá outras providências .Disponível em: <http:/www.planalto.gov.br/ccivil_03/_ato2011- 2014/2011/lei/ 112527.htm>. Acesso em: 9 ago. 2017.

BOBBIO, Norberto. O futuro da democracia: uma defesa das regras do jogo. 6 . ed. Rio de Janeiro: Paz e Terra, 1986, p. 18. V.63.

BRESSER-PEREIRA, Luiz Carlos. A reforma gerencial do Estado de 1995. Revista de Administração Pública, Rio de Janeiro, v. 4, n. 34, pp. 7-26, jul./ago. de 2000.

BUSCA por vantagens financeiras desvia MP e Defensoria de função cidadã, diz pesquisadora. UOL. Notícias, Política. Disponível em:

$<$ https://noticias.uol.com.br/politica/ultimas-noticias/2017/08/05/busca-porvantagensfinanceiras-desviam-mp-e-defensoria-de-funcao-cidada-diz-autora-de-estudo.htm>. Acesso em: 6 jul. 2017.

CALLEGARI, José Antônio. Ouvidoria de Justiça: cidadania participativa no sistema judiciário. Curitiba: Juruá, 2014.

CANOTILHO, Jose Joaquim Gomes. Direito Constitucional e Teoria da Constituição. 3.ed. Lisboa: Almedina, 1998, p. 289.

CARVALHO FILHO, José dos Santos. Conselhos Nacionais da Justiça e do Ministério Público: complexidades e hesitações. In: Revista Interesse Público. Belo Horizonte, ano 12, n. 63, set./ out. 2010, pp. 15-38. 
COMPARATO, Fábio Konder. O Poder Judiciário no regime democrático. Estud. av., São Paulo, v. 18, n. 51, p. 151-159, Aug. 2004. Available from

$<$ http://www.scielo.br/scielo.php?script=sci arttext\&pid=S010340142004000200008\&lng=en\&nrm=iso $>$. access on 04 Aug. 2020. https:// doi.org/10.1590/S0103-40142004000200008.

CNJ. Accountability. Disponível em: <http://www.cnj.jus.br>. Acesso em: 15 mar. 2017.

CNJ. Censo do Judiciário. Disponível em: http://www.cnj.jus.br/pesquisas-judiciarias/censodopoder-judiciario/743-gestao-planejamento-e-pesquisa/censo-do-judiciario. Acesso em: 22 jul. 2017.

CNJ. A Estratégia do Conselho Nacional de Justiça, fev. de 2014. Disponível em: < https:// www.cnj.jus.br/wp-content/uploads/2011/02/planejamento_estrategico_2014.pdf $>$. Acesso em: 04 ago. 2020.

CNJ. Planejamento Estratégico CNJ 2015-2020, 2018. Disponível em: https://www.cnj.jus. br/wpcontent/uploads/conteudo/arquivo/2018/10/4d3f593f899f7177e4edadfebd7ef42c.pdf $>$. Acesso em: 04 ago. 2020.

CNJ. Relatórios por Tribunal. Censo. Disponível em: $<$ http://www.cnj.jus.br/ pesquisasjudiciarias/censo-do-poderjudiciario/79054relatorios-por-tribunal $>$. Acesso em: 22 jul. 2017.

CONSELHO NACIONAL DE JUSTIÇA. Disponível em: <http://www.cnj.jus.br/ pesquisasjudiciarias>. Acesso em: 21 jul. 2016.

CONSELHO NACIONAL DE JUSTIÇA. Disponível em:

$<$ http://www.stj.jus.br/static_files/STJ/Institucional/ Gest\%C3\%A3o\%20estrat\%C3\% A9gica/1_ plano_estrat_14dez16.pdf $>$. Acesso em: 9 nov. 2016.

DALLARI, Dalmo de Abreu. O poder dos juízes. 3. ed. São Paulo: Saraiva, 2008.

FLUHR, Fernanda Adriano. A Jurisdição Constitucional e o Conselho Nacional de Justiça: a possibilidade do exercício do controle concentrado de constitucionalidade pelo CNJ.

Dissertação de Mestrado apresentada à Universidade Católica de Pernambuco. Recife, 2011.

GIDDENS, Anthony. As consequências da modernidade. Tradução: Raul Fiker. São Paulo: EDUNESP, 1991.

GOYARD-FABRE, Simone. Os princípios filosóficos do direito político moderno. Tradução: Irene A. Paternot. São Paulo: Martins Fontes, 2002.

HABERMAS, Jürgen. A nova obscuridade. Tradução: Luiz Repa. São Paulo: EDUNESP, 2015.

HABERMAS, Jürgen. Direito e democracia. Tradução: Flávio Breno Siebeneichler . Rio de Janeiro: Tempo Brasileiro, 2011. v. 2. 
HABERMAS, Jürgen. El discurso filosófico de la modernidad. Tradução: Manuel Jimenéz Redondo. Madrid: Taurus Humanidades, 1993.

HABERMAS, Jürgen. Para a reconstrução do materialismo histórico. Tradução: Carlos Nelson Coutinho. 2. ed. São Paulo: Brasiliense, 1990.

HABERMAS, Jürgen. A inclusão do outro: estudos de teoria política. Tradução: George Sperber; Paulo Astor Soethe. São Paulo: Loyola, 2002.

HANSEN, Gilvan Luiz. A gestão de pessoas em instituições do Poder Judiciário. In: Sociologia Jurídica. BANNWART JÚNIOR, Clodomiro José; CACHICHI, Rogério Cangussu Dantas (Orgs.). Sociologia jurídica. Belo Horizonte: Arraes, 2015.

LUBENOW, Jorge Adriano. Esfera pública e democracia deliberativa em Habermas: modelo teórico e discursos críticos. Kriterion, Belo Horizonte, v. 51, n. 121, p. 227-258, June 2010. Available from $<$ http://www.scielo.br/scielo.php?script $=$ sci arttext\&pid=S0100512X2010000100012\&lng=en\&nrm=iso $>$. access on 04 Aug. 2020. http:// dx.doi.org/10.1590/S0100-512X2010000100012.

MARQUES NETO, Floriano de Azevedo. Os grandes desafios do controle da administração pública. 10-artigos-controle-administração-publica. Fórum de Contratação e Gestão Pública - FCGP. Belo Horizonte, ano 9, n, 100, abril,10. E book. Biblioteca Digital do Fórum de Direito Público. Disponível em <https://www.passeidireto.com/arquivo/16720388/ebook-10artigoscontrole-administracao-publica> Acesso em: 20 maio, 2016.

MALUF, Paulo José Leonesi. Conselho Nacional de Justiça. Análise de sua competência disciplinar. Dissertação de Mestrado apresentada ao Programa de Pós-Graduação da Faculdade de Direito da Universidade de São Paulo, 2013.

MEDAUAR, Odete. Direito Administrativo moderno. São Paulo: Editora Revista dos Tribunais, 2015.

RAMOS, Guerreiro. The New Science of Organizations: Reconceptualization of the Wealth of Nations. Press University of Toronto, 1984.

RELATÓRIO ICJ Brasil São Paulo: DIREITO SP - Índice de Confiança na Justiça Brasileira - ICJBrasil. $1^{\circ}$ semestre / 2013. Disponível em:

$<$ http://bibliotecadigital.fgv.br/dspace/handle/10438/6618>. Acesso em: 12 set. 2015.

RELATÓRIO ICJ Brasil São Paulo: DIREITO SP - Índice de Confiança na Justiça Brasileira ICJBrasil. $2^{\circ}$ semestre / 2013. Disponível em:

$<$ http://bibliotecadigital.fgv.br/dspace/handle/10438/6618>. Acesso em: 12 set. 2015

RELATÓRIO ICJ Brasil São Paulo: DIREITO SP - Índice de Confiança na Justiça Brasileira

- ICJBrasil. $1^{0}$ trimestre / 2014. Disponível em:

$<$ http://bibliotecadigital.fgv.br/dspace/handle/10438/6618>. Acesso em: 12 set. 2015.

RELATÓRIO ICJ Brasil São Paulo: DIREITO SP - Índice de Confiança na Justiça Brasileira

- ICJBrasil. $2^{\circ}$ trimestre / 2014. Disponível em: 
$<$ http://bibliotecadigital.fgv.br/dspace/handle/10438/6618>. Acesso em: 12 set. 2015.

RELATÓRIO ICJ Brasil São Paulo: DIREITO SP - Índice de Confiança na Justiça Brasileira ICJBrasil. $2^{\circ}$ semestre / 2015. Disponível em:

$<$ http://bibliotecadigital.fgv.br/dspace/handle/10438/6618>. Acesso em: 12 set. 2015.

RELATÓRIO ICJ Brasil São Paulo: DIREITO SP - Índice de Confiança na Justiça Brasileira

- ICJBrasil. $1^{0}$ semestres / 2016. Disponível em:

$<$ http://bibliotecadigital.fgv.br/dspace/handle/10438/6618>. Acesso em: 12 set. 2015.

RELATÓRIO ICJ Brasil, São Paulo: DIREITO SP - Índice de Confiança na Justiça Brasileira - ICJBrasil. $1^{0}$ trimestre / 2012. Disponível em:

$<$ http://bibliotecadigital.fgv.br/dspace/handle/10438/6618>. Acesso em: 12 set. 2015.

SADEK, Maria Tereza (Org.). Reforma do Judiciário. Rio de Janeiro: Centro Edelstein de Pesquisas Sociais, 2010.

SADEK, Maria Tereza. Controle externo do Poder Judiciário. In: Reforma do Judiciário. São Paulo: Fundação Konrad Adenauer, 2001.

STJ. Plano Estratégico Superior Tribunal de Justiça 2010-2014. Brasília - DF, 2012.

Disponível em: $<$ http://www.stj.jus.br/file_source/STJ/Institucional/Gest $\%$ C3\%A3o\%20 estrat\%C3\%A9gi ca/plano\%20estrategico\%202014.pdf>. Acesso em: 04 ago. 2020.

STJ. Plano STJ 2020: a base para o futuro que queremos / Superior Tribunal de Justiça. Ed. rev. e atual. setembro 2018. -- Brasília: Superior Tribunal de Justiça, 2018.

TRT. $1^{\text {a }}$ Região. Disponível em:

$<$ http://portal.trt1.jus.br:7777/pls/portal/docs/PAGE/GRPPORTALTRT/

PAGADMINISTRATIVO/SUBTRANSPARENCIATRTRJ/SUBANEXOVIII/PLANILHA\% 20FINAL $\% 20$ NOVEMBRO $\% 2012 \% 20$ NOVO $\% 20$ PADR $\%$ C3\%83O $\% 20$ SEM $\% 20$ NOMES $>$. Acesso em: 9 jun. 2016.

TENÓRIO, Fernando Guilherme. Gestão social: uma perspectiva conceitual. Revista de Administração Pública, v. 32, n.5, 1998.

WAMSER, 2017. Disponível em: <http://a-secretaria-que-faz.blogspot.com.br/2011/07/ omodelo-tradicional-de administracao.htm>. Acesso em: 7 jun. 2017.

Como citar DE PAIVA, Marcella da Costa Moreira. HANSEN, Gilvan Luiz. DE MATTOS, Simone Brilhante. Democracia e poder judiciário: estudo sobre legitimidade e institucionalização da opinião e da vontade. Scientia Iuris, Londrina, v. 24, n. 3, p. 50-72, nov. 2020. DOI: 10.5433/2178-8189.2020v24n3p50. ISSN: 2178-8189.

Recebido em: 22/08/2020

Aprovado em: 22/09/2020 